\title{
Colored Coating Materials with Spectrally Selective Reflectance for Woodland Camouflage Textile Fabrics ${ }^{\dagger}$
}

\author{
Georgiana Cornelia Ispas *, Valentin Raditoiu, Alina Raditoiu, Florentina Monica Raduly, \\ Violeta Purcar, Raluca Manea and Luminita Eugenia Wagner \\ National Research and Development Institute for Chemistry and Petrochemistry ICECHIM, Laboratory of \\ Functional Dyes and Related Materials, 202 Splaiul Independentei, 6th District, 060021 Bucharest, Romania; \\ vraditoiu@yahoo.com (V.R.); alinaraditoiu@yahoo.com (A.R.); radulymonica@yahoo.com (F.M.R.); \\ purcarvioleta@gmail.com (V.P.); raluca_manea1994@yahoo.com (R.M.); luminitawagner@yahoo.com (L.E.W.) \\ * Correspondence: georgiana.ispas23@yahoo.com \\ + Presented at the 15th International Symposium "Priorities of Chemistry for a Sustainable Development" \\ PRIOCHEM, Bucharest, Romania, 30th October-1st November 2019.
}

Published: 15 October 2019

Keywords: hybrids; dyes; camouflage; coatings; reflectance; serigraphy

The camouflage effect aims to reproduce natural or artificial surroundings in terms of color, pattern, texture and gloss [1]. The objective of this work is to obtain pigment materials, with controlled reflectance in the Vis-NIR range, by sequestering some cationic dyes in an achromatic layered silicate, and to use the hybrid pigments in serigraphic pastes for printing camouflage patterns on textile fabrics.

Melacryl dyes (Colorom) were deposited on Kaolinite (Merck) from aqueous solutions, using an ultrasonic processor (Sonics, VCX-750). The colored materials were subsequently used to prepare serigraphic printing pastes by embedding them into a water soluble vinyl acrylic aqueous dispersion self-cross linkable at moderate temperature-Tubvinyl $235 \mathrm{MC}(\mathrm{CHT})$, using an automatic pigment mulling machine (J. Engelsmann AG).

A high coloring power cationic dyes, with increased affinity for achromatic Kaolinite filler, were selected in order to obtain hybrid pigments having fundamental colors. The camouflage colors were obtained by mixing the hybrid pigments in certain ratio, in order to fulfill the shades, which mimic the Vis-NIR reflectance pattern of forest-type surroundings. In order to tune-up the reflectance profile, white and black extender pigments, with optimized NIR reflectance, were added in small proportions to the mixture. The acrylic resin was selected because it provides the optimum value of the ratio between the refractive index of the hybrid pigments and the binder, in order to minimize the emission from the surface due to backscattering. It is worth mentioning that the printing pastes exhibit low absorption throughout the entire spectral range of interest.

Hybrid materials with fundamental colors were successfully obtained. Some colored coating materials, having military recommended spectral characteristics for woodland camouflage pattern, were prepared using trichromy formulation (Figure 1). Textile fabrics, printed with the serigraphic pastes, meet the requirements of the military camouflage standards and specifications. 


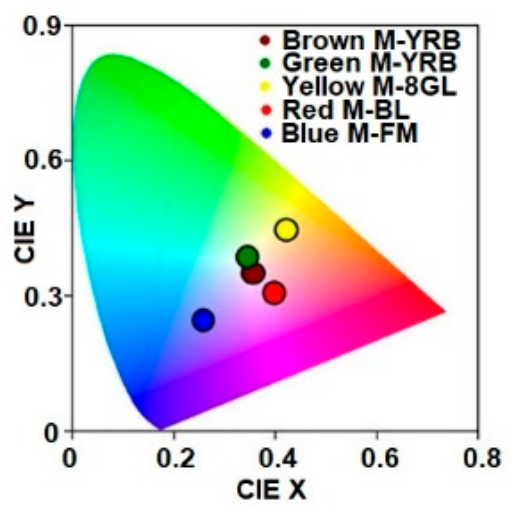

Figure 1. Chromaticity coordinates of colored fabrics.

Funding: The work on this paper was supported by a grant of the Romanian Ministry of Research and Innovation, PCCDI UEFISCDI, project number PN-III-P1-1.2-PCCDI-2017-0395 within PNCDI III (no 70 PCCDI/ 2018, PC5-MULTICAM).

\section{Reference}

1. Rubeziene, V.; Padleckiene, I.; Baltusnikaite, J.; Varnaite, S. Evaluation of camouflage effectiveness of printed fabrics in visible and near infrared radiation spectral ranges. J. Mater. Sci. 2008, 14, 361-365.

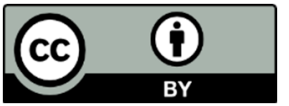

(C) 2019 by the authors. Licensee MDPI, Basel, Switzerland. This article is an open access article distributed under the terms and conditions of the Creative Commons Attribution (CC BY) license (http://creativecommons.org/licenses/by/4.0/). 